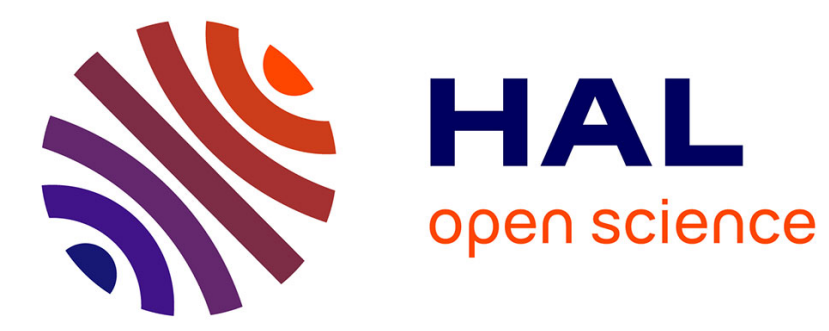

\title{
An analysis scheme for modeling the functioning of a tomato canopy
}

Philippe Bussières, Y. Dumas

\section{To cite this version:}

Philippe Bussières, Y. Dumas. An analysis scheme for modeling the functioning of a tomato canopy. 4. International Symposium, Feb 1991, Mendoza, Argentina. hal-02772238

\section{HAL Id: hal-02772238 \\ https: / hal.inrae.fr/hal-02772238}

Submitted on 4 Jun 2020

HAL is a multi-disciplinary open access archive for the deposit and dissemination of scientific research documents, whether they are published or not. The documents may come from teaching and research institutions in France or abroad, or from public or private research centers.
L'archive ouverte pluridisciplinaire HAL, est destinée au dépôt et à la diffusion de documents scientifiques de niveau recherche, publiés ou non, émanant des établissements d'enseignement et de recherche français ou étrangers, des laboratoires publics ou privés. 


\title{
Fourth International Symposium on Processing Tomatoes
}

\author{
Editors \\ Cosme A. Argerich \\ Humberto R. Galmarini
}




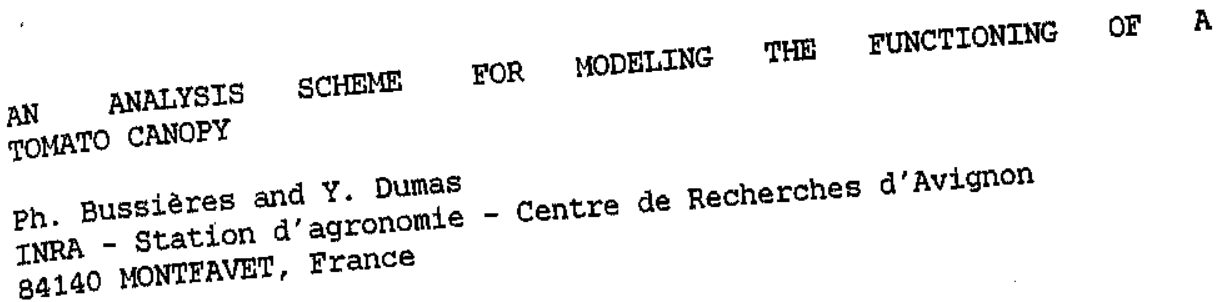

An analysis scheme of the functioning of a tomato canopy is presented. It is the basis of the thatcates the variables and the (Bussieres, 1990). This schem into account and those which are factors which have biferents levels are considered, on the prospects for

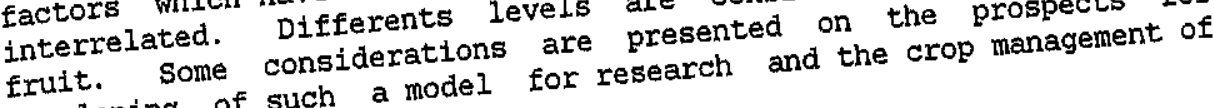
developing of such

the processing tomato.

\section{Introduction}

It is important to make a model of the tomato field in order to forecast its functional operation based on the factoment techniques. depends and to soundly decide upon the of a plant row model to Bussières (1990) has bullt a framewing to harvest, and pointing out simulate it from day to day frow. Such a model requires a detailed the variability inside the row any moment $t$. At a first level of analysis of the functionis consists in listing the various varlabed. research, such an analy in determining those which are inter points for and factors involved an the accomplished analysis and sompovement and We present a scheme of the accomplisospects for improvement and consideration

utilization.

The aim of this presentation is to show the direction in which knowledge and decision making possiblitties the evolution of tecnical crop management will probably evisue). Processing tomato crop should operations (Dumas, 1991, sameling efforts, already undertaken (W1lson indeed be the subject of modeling is the tomato grown under shelter et al., 1987, for instance), as ideld crops.

and also many other open 1teld cy

\section{Methods}

\subsection{Analysis scheme}

The study was undertaken using a "system approach". Some definitions and principles about this type of approach as a group of given by Gras (1990). A system isying such a system consists, on the mutually interrelated units its elements and, on the other hand, in one hand, in identifying lts elongly interrelated. According to osty determining those which are stuch a system approach means to first (cited in Gras, 1990) 
consider the whole before studying the parts which can be successfully studied in depth". This approach reduces the risk of overlooking the relationshtps which exist between the subsets, which could occur if they are studied too soon.

During the first stage of such an approach, one could limit oneself to simply noticing the important relationships which exist between the elements. A chart can then suffice. The chart in Figure 1 gives the variables and their
interrelationships at the time $t$ in the plant row. Only the most important ones in the structure of the row plant have been considered here. These variables take place at different levels

- the plant row itself,

- the medium,

- the canopy,

- within the latter, the plant,

- then the fruiting truss,

- and the bud.

Many variables are considered through :

- their state at the time $t$,

- their variation rate during an interval dt following $t$.

\subsection{Experimental data}

The experimental data used in this study came from an

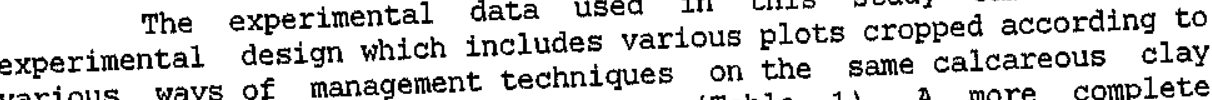
various ways three successive years (Table 1). A more complete description was provided by Dumas et al. (1983).

Table 1 - Short description of the studied fields.

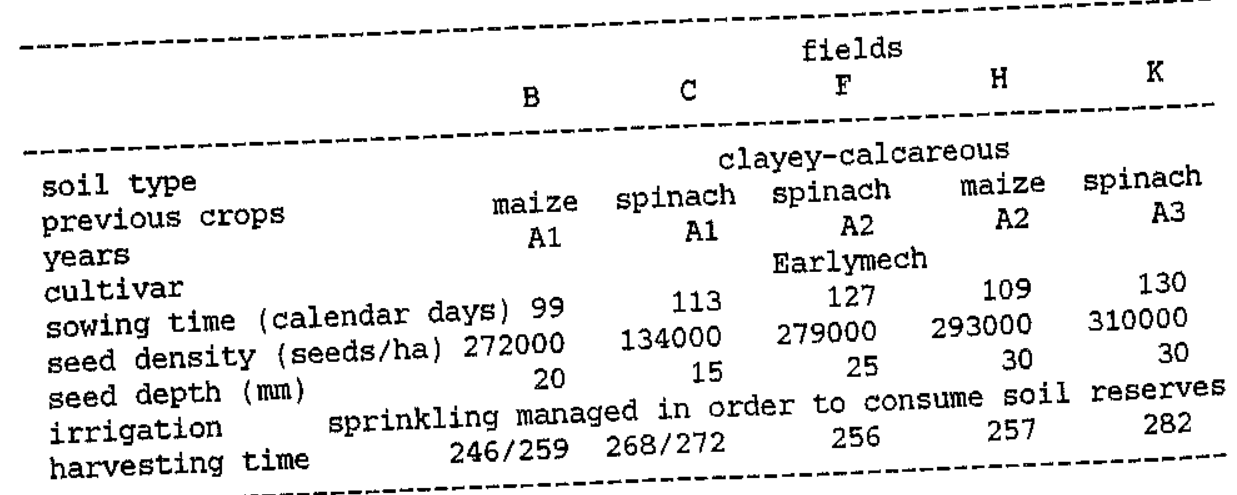

\section{Discussion and conclusion}

The scheme transposed into a quantitative model has allowed fairly satisfactory simulations of tomato crop rows (Bussières, 1990). 


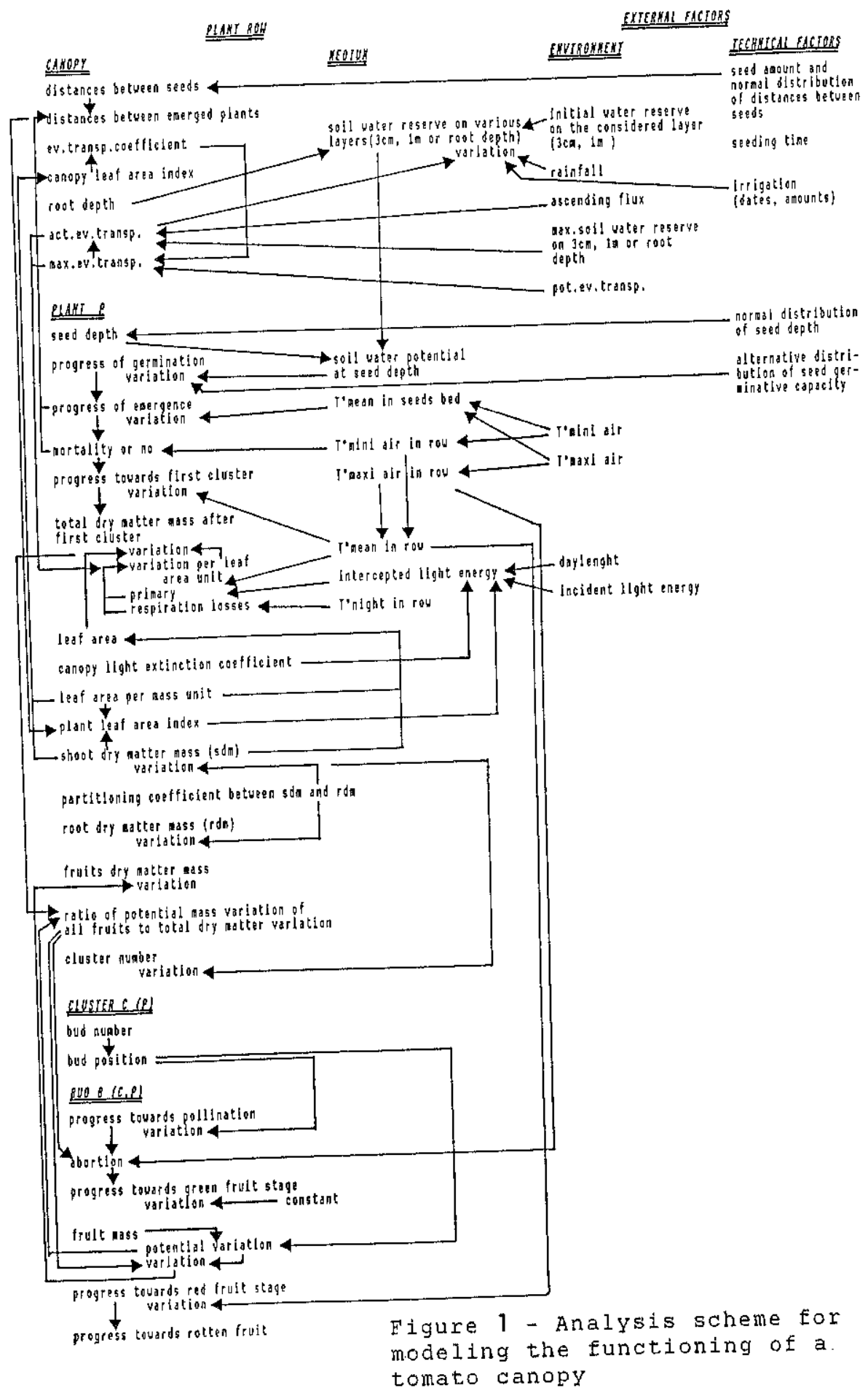




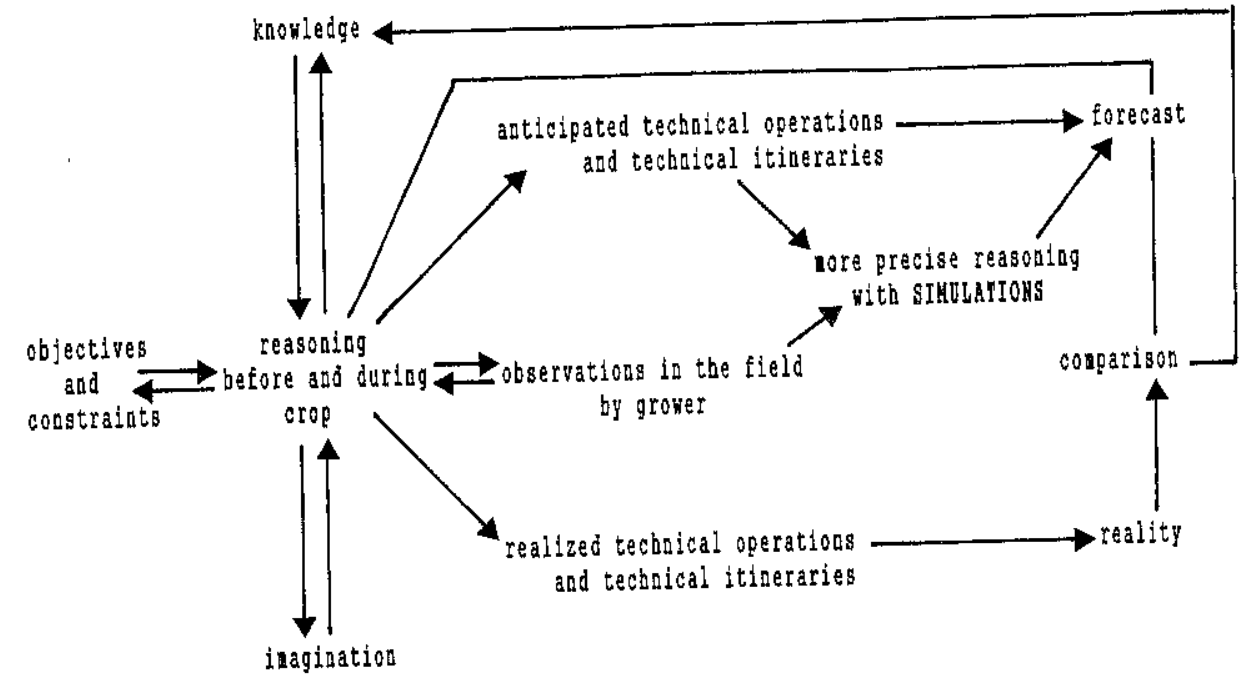

Figure 2 - Diagram showing the elaboration of technical itinerary and the position of simulation

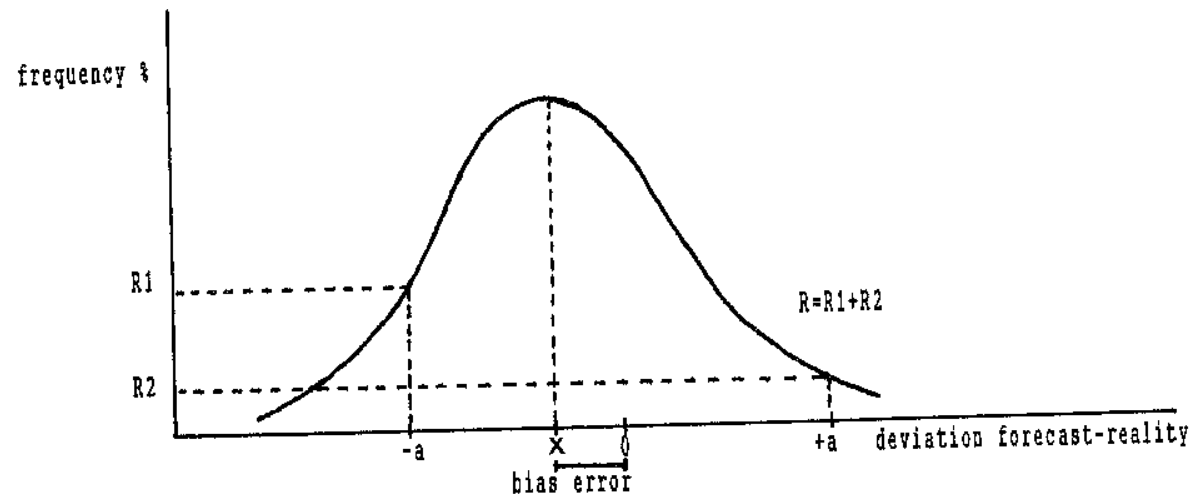

Figure 3 - Supposed distribution curve of deviation between forecast and realtty for field yield 
In this first stage, however, many factors and vartables have not taken into account. The analysis must, therefore, be and studied in greater depth, for instance, by introducing concerns, for which submodels exist. These the nitrogen nutrition to nitrogen avallabllity in the soil and are submodels are relative to adaptations enabled by the likely to be usable once they undergo to the nitrogen effects on analysis scheme, or they are relatiala and Dumas, 1991, same issue).

Such a scheme constitutes an integration of the knowledge which exists at varlous levels and it expresses the variability within space and time which appears in each of them. It shows that the explanation of a given level does not only depends on the lower levels.

It should, therefore, help to know better and model the functioning of the field, by Identifying the lacks of knowledge and further necessary research and by helping to organise and conduct such research. Indeed, in particular, by considering the various enhance the possibility:
- of control in open field and thus of confrontation between simulated and observed values,
- of modeling by using more empirical knowledge where local or momentary conditions at the field level make them acceptable when no knowledge of greater depth exists.

Concurrently, this way should be of use to imagine, perfect and real time pllot crop management schedules which are adapted to given and constraints. Indeed, tecnical cholces result from successive confrontations which are made by the growerfects of the objectives and constraints and the forecasts of the ef improvement of these considered tecnical operations (Figure 2 ) accuracy (decrease of bias forecasts depends on the increase of the $R$ for them to be different. error) and on the reduction of the rlsk $R$ fiven threshold a (Figure from the reality by a value greater that an expert will forecast the 3). For instance, one can assume that an ha-1, but that in 20 cases yleld average of 100 tomato flelds at the forecasted one by more than the achieved yield will diverge from thowledge which could allow 30 t.ha-1. Conseguently, with the present lema, the most interesting a mean yield satisfactory for the also for the canning industry in improvement for the growers - but also - to reason crop management in terms of harvesting date, for exon of the risk R. It should result given conditions is the reduction of to take into account a great from the amelioration of the capacif it is approximattve for each number of factors and mecanisms, even if 1 th of them. In particular, it is abvious thoint or transitory variations value of the factors, their very pinpoin the field or transient (e.g. appearance of a pest localin the functioning of the field and climatic event) can be decisive in the fyche and the resulting must be considered. The present tyables into account. However, the model should help to take these variables into account the vartability 
of these input factors. Even if these values can be fairly well known for the environment (sotl variations, etc...) the variations of the technical factors will probably be more difficult to know (irrigation or seeding heterogeneities, etc...). This will require research of data of these variation factors and als observation methods by the growers.

\section{Références}

Bussières Ph., 1990. Canevas de modèle d'une ligne de plantes de tomate explicltant sa vartabilite spatiale. Acta Horticulturae, Third international symposium on processing tomatoes, 277, 221227.

Crop management for processing tomatoes in the year 2000. Acta Horticulturae, 4th int
processing tomatoes (present issue).

Dumas Y., Vergniaud P., Bussières Ph., 1983. Présentation d'une étude experimentale de divers modes de conduite de la tomate de plein

champ dans differentes successions de culture. 23ème colloque Société Française paris.

Gras R., 1990. L'analyse par les systèmes. Groupe de Recherches Non Sectorielles, I.N.R.A., Paris.

Suniaga Quijada and Dumas Y. and Bonafous M., 1991. Growth and development of young tomato plants under nitrogen deficiency: Acta Horticulturae, 4th international symposium on processing tomatoes (present issue). Wilson L.T, Guttierez A.P. ' Tennyson R., Zalom F.G., 1987. A
physiological based model for tomatoes: crop and pest management. second international symposium on processing tomatoes. $200,125-132$. 